\title{
The efficacy of training in dynamic psychotherapy
}

\author{
Many Morton and James Bailey
}

\begin{abstract}
The efilcacy of troining in dyncmic poychothercipy was aseosesed by sonding a questionnolise to al vitting thorcplats (nioinees) in the Lelceeter Poychotherapy Deportment. Quedtions were directed fowards the eflect of training on trainees' work in nonpoychothorapy seltinges. Trainees noted inprovements in communication skilis, casesement/reformal skills, andity and boundary manogement and overall manogement of the therepoutic relationstip. improvement wos atso noted in lob soltidaction and moltucition af work. These improvements were more prominont in traineses who had hod more than two years' training.
\end{abstract}

Training in dynamic psychotherapy is recognised as an important part of training in psychiatry for all mental health professionals. This importance is emphasised in the College guidelines for psychotherapy training as part of general professional training (Grant et al. 1993). That training, even at an introductory level, can benefit people in their general psychiatric work (Hughes \& Halek, 1991). In their study, a one year course introducing psychodynamic principles to nurses resulted in significant changes in the nurses' confidence, competence and understanding of their work-valuable assets in any psychiatric setting.

For many years, the Leicester psychotherapy service has provided training to a wide range of people working in different mental health settings. The central component of this training is intensively supervised clinical work in the psychotherapy department. Trainees come as 'visiting therapists' seeing patients in exchange for supervision. Academic seminars at both introductory and more advanced levels supplement this clinical core.

The present study attempts to evaluate this psychotherapy training. The focus of attention in the study is the effect of training on a person's work outside the psychotherapy department.

\section{The setting}

Visiting therapists in the Leicester Psychotherapy Department are supervised on their work in individual psychotherapy. Supervision is in groups of two to four people for 1.5 hours weekly. Academic seminars vary in content but each year an introductory seminar series is held, with at least one other seminar group at a more advanced level.

\section{The study}

A questionnaire was sent to all visiting therapists seeing at least one patient in the psychotherapy department ( $n=27)$. The questions were directed towards the effect of psychotherapy training on a person's general work. Background information was sought on the trainee's current post, previous training in dynamic psychotherapy and the number of years spent in supervision at the department.

The main part of the questionnaire asked trainees about their perceived development of a range of skills, both in terms of their understanding and management of patients since commencing their psychotherapy training. Change was scored on a five point scale from 'decreased skill' to 'great improvement'. The questions in this section asked about the following areas:

(a) communication skills, e.g. listening skills

(b) assessment and referral skills, e.g. understanding patient's problems in psychodynamic terms

(c) anxiety and boundary management, e.g. managing acting out behaviour

(d) therapeutic relationship, e.g. understanding of transference and countertransference.

A final section of the questionnaire asked trainees about the effect of psychotherapy training on their motivation at work and job satisfaction. 
Table 1. Respondents scoring 4 or 5 (improvement or great improvement) for questionnaire varlables when stratified by length of time in supervision

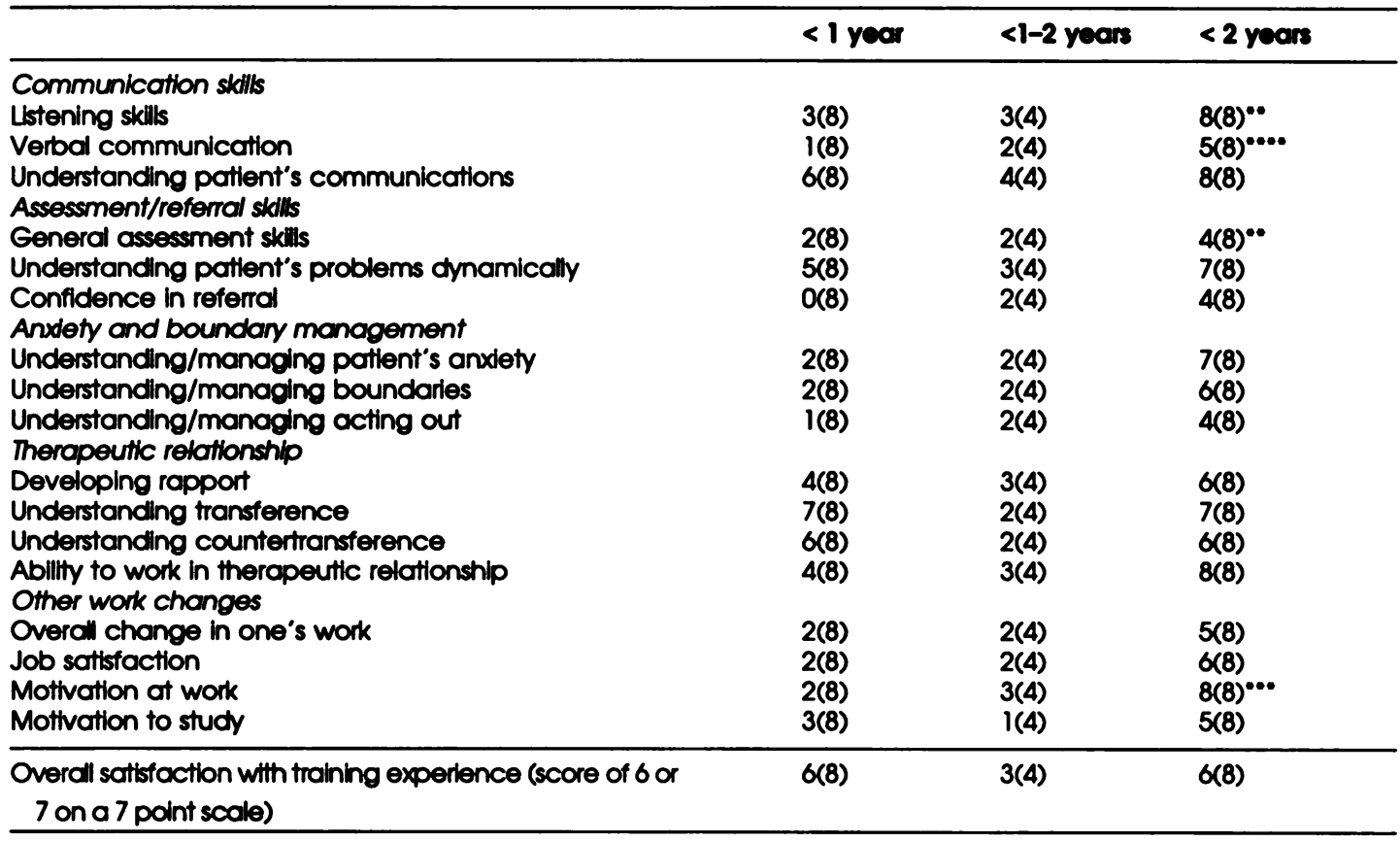

$\cdots p<0.001$

$\cdots p<0.01$

$\because P<0.02$

$-P<0.05$

Statistical analysis (comparing the 'less than one year' cohort with the 'greater than two years' cohort) using Fisher's exact test

Results were stratified by length of time in supervision at the Psychotherapy Department.

\section{Findings}

Out of 27 trainees, 20 returned the completed questionnaires. There were nine doctors (mostly registrars), six nurses (four community psychiatric nurses, one ward sister, and one clinical nurse specialist with the eating disorders team), three occupational therapists and two social workers. Most had had no previous training in psychotherapy.

\section{Number of years in supervision}

Eight trainees had less than one year of supervision in the department (seven of these were doctors). Four had between one and two years of supervision and eight had more than two years. The longest period in supervision was seven years.

\section{Development of skills}

Of importance is that no trainee reported any decreased skills. It is, of course, unlikely that a trainee would perceive a decrease in skills as a result of any training experience, even a bad one. In our analysis, we looked for clear indications of change, so scores of 3 (indicating slight improvement) were not considered as positive change.

A definite trend emerged from the responses: the longer one has spent in supervision, the greater the perceived skdlls development. Table 1 shows the number of respondents scoring 4 or 5 (improvement or great improvement) across the range of variables when scores were stratified by length of time in supervision'. The trend overall is for an improvement in skills the longer one has been in supervision. However, this relationship is not always a linear one. The cohort with one to two year's experience of supervision seem less confident about their 
grasp of concepts such as transference and countertransference. Given these atypical results for the middle cohort, it was not included in the statistical analysis, a single comparison being made between the "less than one year's supervision' cohort with the 'greater than two year's supervision' cohort. The following changes achieved statistical significance (using Fisher's exact test) when these two cohorts were compared.

$$
\begin{array}{ll}
\text { Improved verbal communication } & P<0.001 \\
\text { Improved listening skills } & P<0.02 \\
\text { Improved ability to understand } & \\
\text { and manage patients' anxiety } & P<0.02 \\
\text { Increased confidence in referral } & P<0.05 \\
\text { Increased ability to work in the } & \\
\text { therapeutic relationship } & P<0.05
\end{array}
$$

It was not possible to analyse differences across professional groups as, of the nine doctors, seven had less than one year's supervision experience and this would be a confounding variable in the stratification. Registrars normally stay for at least two years of supervision but, at the time the questionnaire was sent, there were a number of doctors relatively new to the department.

\section{Other work changes}

Trainees noted improvements in their overall job satisfaction and motivation at work even as a consequence of less than one year of training in dynamic psychotherapy. For those trainees with more than two years of supervision, 75\% noted improved job satisfaction with $100 \%$ feeling an improvement in their motivation at work (see Table 1). These results indicate that training in dynamic psychotherapy is a good influence on trainees' work.

\section{Trainees' written comments}

Most trainees added their own comments in addition to fllling in the ratings for each question. Comments described their experiences:

of doing something new or different, e.g. "I allow things to take their course and don't rush"

of being able to apply their knowledge in specific areas, e.g. "Importance of boundaries particularly useful when dealing with bulimic patients" of the learning process, e.g. "I can contain my patients' anxiety to a much greater degree knowing there is meaning - anxiety does not occur in a vacuum".

The comments gave a sense of the wide variation in individuals' learning needs and styles and in their perception of the training attachment as a learning experience.

\section{Comment}

This study shows that trainees gain much from their training in dynamic psychotherapy. They report significant changes in their knowledge base, clinical practice and self awareness as clinicians.

\section{The process of learning psychotherapy}

The longer one has been in training and supervision, the greater is the perceived development of skills. However, within this picture, a number of interesting patterns emerge. Some skills develop at an early stage. The majority of trainees with less than one year's experience see an improvement in their understanding of patient's communications, of transference and of countertransference in the patient/therapist relationship. They also see themselves as being more aware of understanding the patient's problems in dynamic terms. Other skills - management of patient's anxiety and boundary management, overall ability to work within the therapeutic relationship - take more time to develop.

In any developmental process, some things are learnt more quickly than others. It may be that the process of learning dynamic psychotherapy parallels the processes involved in learning a language. In the early stages, one learns to understand the language, its structure and meaning. It is only at a more advanced stage that the ability to use the language for oneself and with others develops. The skills which take time to develop may be related more to the management of the therapeutic process rather than the understanding alone.

Even considering individual skills, e.g. understanding of transference, development is not always a linear process and there seems to be a drop in confidence in the one to two year period (see Table 1). It is unlikely that the understanding gained in year one has been lost. It may be that 'understanding' of a concept occurs at many different levels. At an early stage, trainees may have a superficial 
understanding of 'transference'. With further training and experience they realise the complexity of the concept and are more aware of the limitations of their knowledge. Subsequently, a richer and more in depth understanding develops.

Many theories of learning stress the active role of the learner in constructing personal understanding. Kolb (1983) outlined a learning cycle of four phases.

The first phase involves a 'concrete experience' in which the trainee gains basic tanglble knowledge. This could come from starting therapy with a patient, learning some basic definitions.

Next, there is a phase of 'observation and reflection' which may get under way as the trainees begins to discuss their case in supervision and listen to other trainees' experiences.

Third, is a phase of 'forming abstract concepts and making generalisations' which takes time to achieve and is assisted through theoretical discussions in seminar and supervision groups.

The fourth phase involves 'testing the implications of concepts in new situations'. This phase enables the trainees to apply their experience in day to day practice.

\section{Professional differences}

It was not possible to analyse differences across professional groups, as most of the doctors had less than one year's experience of supervision. It is likely that doctors will differ from other trainees. They are required to have psychotherapy training whereas the other trainees will have sought out the training opportunity. Doctors may also be wanting a different experience to other professionals, seeing psychotherapy training as part of their general psychiatric training. However, the results of this paper indicate that to consolidate their psychotherapy skills, a period of at least two year's supervision would be recommended, as is emphasised in the College guidelines (Grant et al, 1993).

The impact of psychotherapy training on trainees' general work

Training takes time but the study indicates that it is time well spent. The beneficial effect of training on people's motivation to work and job satisfaction is clear from and will be of interest to managers. Specialist psychotherapy departments have always seen training as an important part of their role and this study underlines the effectiveness of this function. Purchasers too have an interest in training and will find it helpful to have demonstration of its value.

Our questionnaire has only touched on what is a huge area concerning the learning process itself. It would be valuable to look in more depth at the learning process over time, perhaps with a more refined instrument. It would also be of interest to focus further on just how training in dynamic psychotherapy might inform a trainee's work in other areas of psychiatry.

\section{References}

Grant, S., Holmes, J. \& Watson, J. (1993) Guidelines for psychotherapy training as part of general professional psychiatric training. Psychiatric Bullettn, 17, 695-697.

HuGHES, P. \& HALEK, C. (1991) Training nurses in psychotherapeutic skdlls. Psychodynamic Psycho therapy. 8, 115-123.

KoLB, D.A. (1983) Experiential Learning: experience as the source of learning and development. New York: Prentice Hall.

Mary Morton, Senior Registrar in Psychotherapy: and James Balley, Principal Psychotherapist, Dynamic Psychotherapy Service, Humberstone Grange Clinic, Thurmaston Lane, Leicester LE5 OTA 